24. PTI.Biocon gets DCGI nod for use of Itolizumab for treatment of COVID-19 patients. Economic Times. 2020 Jul 11 [cited 2020 Jul 23]. Available from:https:// health.economictimes.indiatimes.com/news/pharma/biocon-gets-dcgi-nod-for-use-of-itolizumab-for-treatment-of-covid-19-patients/76916677

25. Somers EC, Eschenauer GA, Troost JP, Golob JL, Gandhi TN, Wang L, et al. Tocilizumab for treatment of mechanically ventilated patients with COVID-19. Clin Infect Dis. 2020 Jul 11; ciaa954. doi: 10.1093/cid/ciaa954. Epub ahead of print.

26. Rome BN, Avorn J. Drug Evaluation during the COVID-19 Pandemic. N Engl J Med. 2020;382(24):2282-4. doi: 10.1056/NEJMp2009457.

27. Karindalam A. Increase in intake of Ayurvedic immunity boosters as COVID-19 cases rise. The Week. $2020 \mathrm{Jul} 11$ [cited 2020 Jul 22]. Available from: https:// www.theweek.in/news/health/2020/07/12/increase-in-intake-of-ayurvedic-immunity-boosters-as-COVID-19-cases-rise.html.

28. Rao SR. Immunity-boosting Vitamin C tablets in short supply, say Bengaluru chemists. Times of India. 2020 Jul 16[cited 2020 Jul 22]. Available from: https://imesofindia.indiatimes.com/city/bengaluru/immunity-boosting-vitamin-c-tablets-in-short-supply-say-chemists/articleshow/76987623.cms.

29. Jackson LA, Anderson EJ, Rouphael NG, Roberts PC, Makhene M, Coler RN, et al. An mRNA Vaccine against SARS-CoV-2 — Preliminary Report.NEngl J Med. 2020 Jul 14. Epub ahead of print

30. Computational Mathematics Group (CMG). PDE-based modelling of COVID-19 infections. Bangalore, India; CMG, Indian Institute of Science. Updated 2020 Jun 18 [cited 2020 Jul 22]. Available from: https://cmg.cds.iisc.ac.in/COVID/

31. World Bank. Death rate, crude (per 1,000 people) - India. 1960-2018 [cited 2020 Jul 22]. Available from: https://data.worldbank.org/indicator/SP.DYN. CDRT.IN?locations=IN.

32. Ministry of Home Affairs. Government of India. Office of the Registrar General \& Census Commissioner. Causes of Death Statistics. New Delhi; MoHA;2020. Available from:https://censusindia.gov.in/vital_statistics/causesofdeath.html. Accessed on July 22, 2020.

\title{
DNAR Guidelines: Supporting end-of-life decisions
}

\section{OLINDA TIMMS}

\section{Keywords: DNAR, end of life decisions, surrogate decisions, patient autonomy}

The Indian Council of Medical Research Consensus Guidelines on 'Do Not Attempt Resuscitation' (DNAR) were published in the April 2020 issue of the Indian Journal of Medical Research (1), and simultaneously in the National Medical Journal of India (2). It is a timely effort at resolving a long-standing clinical dilemma.

DNAR orders are not uncommon in hospital situations at end of life, and while they are legally permissible in many countries, this remains a grey area in India. This policy document attempts to formalise the modalities of a difficult clinical decision that has hitherto been an informal part of professional practice in this country. The guidelines describe the conditions in which DNAR orders may apply, and provides a flow chart of decision-making. It also includes a patient information sheet, FAQs, and a DNAR consent form.

Physicians were always acutely aware of the futility of resuscitation measures in some end-of-life situations, and generally followed the process outlined in this guideline, but it was done informally as there was no medico-legal sanction for the decision. Clinicians are convinced of the necessity of DNAR orders for a sub-group of terminally ill patients, but are wary of social or peer repercussions in this ethical minefield. With these guidelines, doctors will proceed with more confidence, even if the legal liability is not specifically addressed in the guidelines.

To that end, the ICMR tag lends authority to the document, but it still begs the question of why guidelines on clinical practice are being formulated by the National Research Council. The Medical Council of India (Board of Governors) or National Medical Commission that currently regulates medical education and practice should ideally have addressed this aspect of clinical care, as addendum to its ethics regulations. The paucity of practising clinicians and critical care specialists on the "expert group" (1) that created this policy is surprising, and the reasons for this will remain a matter of speculation. Such a document that impacts professional decision-making in clinical end-of-life settings would surely have benefitted from clinical expertise from different parts of the country, through regional consultations. Also conspicuous by their absence are patient groups; directly affected by these guidelines, whose voices and opinions need to be heard. Unfortunately it is top down approaches such as these that have led to confusion and distrust in healthcare, even litigation, when all viewpoints are not represented.

Not surprisingly, some practical details are left unaddressed in the document. There is reference to the "treating physician" but it is unclear who this will be in many hospitals where patients are admitted under "Units" and all doctors of the Unit may see the

Author:Olinda Timms (olindatimms@gmail.com), Division of Health and Humanities, St Johns Research Institute, Bengaluru 560034 INDIA.

To cite:Timms O. DNAR Guidelines: Supporting end-of-life decisions. Indian J Med Ethics. 2020 Jul-Sep; 5(3) NS: 180-1. DOI:10.20529/JJME.2020.081.

OIndian Journal of Medical Ethics 2020 
patient at different times, depending on the duty roster. In such situations, who is the doctor who should speak to the patient/ relative? Should it be the Unit head as this is an important and sensitive decision? In practice, we often see these important communications left to a junior doctor who may be relatively inexperienced. The guidelines do not provide clarity on this aspect. Further, "Physician in charge", as mentioned in the consent form, is non-specific, as many treating doctors/specialists can be "incharge" of the patient at different stages, when the patient is terminally ill. The admitting Unit may even transfer the patient to another Unit based on the immediate need (dialysis, ICU, oncology).

The guidelines mention, "Since CPR is a form of treatment to be provided by the treating physician..." (1: Instructions). This may be inaccurate, as the treating physician may not be around when the patient has a cardiac arrest. If the wishes of the patient are to be respected, the entire team, including nurses in that ward and duty doctors should be informed about the DNAR order. It may even be necessary to flag DNAR orders on the top sheet of the patient record or the bed rail, by a tag or colour code that is clearly visible to the nurse, duty doctor or visiting consultant responding to the "code blue". This could prevent resuscitation by error, even if done inadvertently with the best intentions.

The DNAR tag itself can be ethically problematic, as it singles out these patients who may be viewed differently from other patients. If health workers are adequately sensitised this should not make a difference to care, but the reality of our working conditions and awareness or training levels needs to be taken into consideration. The document should ideally address the ethical use of the DNAR tag in clinical settings.

Since DNAR orders are discussed in a non-emergency context, it would be good to emphasise privacy during this discussion, and the presence of a neutral witness, to preempt any later accusations of incorrect information or coercion. Family members may be overwrought and stressed, unable to fully grasp the terminal nature of the illness, and unprepared to take such difficult decisions. Clinical mediation should be available in case the family disagrees with DNAR orders. If the patient is incapacitated, and a surrogate decision has to be made, there should be two surrogates' signatures as far as possible, on the form. This could preempt disagreements at a later date, given that "a hierarchy of surrogates is not defined in Indian law" (1: Annexure III, Q.6). Clinical ethics committees can play an important role when discussions with family are inconclusive and emotions run high; they can bring objectivity, allow for expression of viewpoints, and clarify the options available. Clinicians too, may feel less isolated in their decision when supported by such a committee.

Though some may consider this a minor issue, the use of the word "vegetative" in the document merits reconsideration (1: Annexure I, Q3). A more sensitive approach, distanced from paternalistic approaches in clinical care, urges us to seek gentler terminology that retains the human aspect of patients, even those in irreversible coma. Though the term is still in use in medical journals, and its alternative "post-coma unresponsiveness" is rather awkward, we could use this opportunity to advance a humane term that preserves the dignity of patients at end of life.

The objectives of this policy can only be met if there is broad-based acceptance and implementation by doctors and hospitals. Given the structural dissimilarities across implementing institutions, private or public, it is not a stretch to imagine some delay and even resistance to translating this policy into practice. Hospitals will have to integrate this policy into their practice protocols, and build the capacity of doctors in handling DNAR decisions. Clarifications may be required on gaps in the document, challenges that may arise, and legal opinion. There is also need for public education and awareness if this is to benefit patients and families involved in these decisions.

On the whole, this is an important policy document that supports doctors in end-of-life decisions while preserving patient autonomy and participation. It deserves to be shared widely for comments, clarifications and legal validation, so that clinicians can make ethical end-of-ife decisions with greater confidence in the best interest of the patient.

\section{References}

1. Mathur R. ICMR Consensus Guidelines on 'Do Not Attempt Resuscitation'. Indian J Med Res. 2020 Apr [cited 2020 Jul 10]; 151(4):303-10. Available from: http://www.ijmr.org.in/text.asp?2020/151/4/303/284215

2. Mathur R. ICMR Consensus Guidelines on ‘Do Not Attempt Resuscitation'. Nat/ Med J India. 2020 [cited 2020 Jul 10]; 32:e1-e8. Epub ahead of print. 